\title{
Discourse First, Cages Second: A New Locus for Animal Liberation
}

\author{
Brianne Donaldson \\ Claremont School of Theology \\ and \\ Center for Neuroeconomics Studies at Claremont Graduate University \\ bri@keefermusic.com
}

\begin{abstract}
The Animal that was named, categorized, and excluded from the human community by the Greeks has seeped into society at multiple points. This Animal now exists in a paradoxical limbo where she is both excluded from social standing and moral consideration while at the same time being included, utilized and discussed within all sectors of society from advertising to philosophy, neuroscience to the pet industry, religion to farming. Thus, animals have been caught up in multiple mechanisms of explanatory terminology, symbolic use, and physical captivity which all work together to create a Discourse of the Animal, which is employed both by those who seek to justify animal use and those who advocate animal liberation. This paper offers a speculative reflection on the development and deployment of the Discourse of the Animal, its reliance on western notions of political subjectivity, and suggests that the biological lives of particular beings invite us beyond discourse to new, though perhaps costly, conceptions of liberation for all beings.
\end{abstract}

\section{Essay}

When I was eight or nine years old, I used to pan for gold in the ankle-deep creek behind my childhood house. For some reason I was sure there was gold in the creek bed, so I'd dig down to the sandy bottom with my screen-bottomed pan, scoop up a pile of dirt and pebbles, and come up shaking the pan back and forth. First the water slipped through the holes, then the tiniest sand fell through, until I was only left with the larger stones. Not gold, to my disappointment, but some lovely stones nonetheless.

One reason for my frustrated efforts was that I didn't know anything about gold. I didn't know where or how to look for it, but had merely mimicked an idea born in my imagination by some movie or story about a traveler heading west to pan for the shiny nuggets in the waters of the California foothills. 
Our quest to understand animals strikes me as similar. Each of us has inherited certain premises about animals: What family they belong to, what we can expect from them, how we can use them, how they define our own humanity, and what roles they can play in our lives. Unfortunately, my finding gold in the shallow Midwestern creek behind my house was as unlikely as my understanding the real biological life, particularity and needs of the cartooned animals that filled my storybooks, whose faces decorated my clothing, who sat in a cage with a spinning wheel on my shelf, or who showed up on my plate in a faceless form. I had always loved animals, or so I thought, but it has taken me over three decades to realize that what I loved might have been nothing more than stones, water and sand. The gold, I'm afraid, still remains quite elusive.

And I'm beginning to wonder if the real gold of the so-called "Animal,"-the singular word observed by philosopher Jacques Derrida to denote "all the living things that man does not recognize as his fellows, his neighbors, or his brothers,"-remains just as hidden from the animal rights movement as a whole (Derrida 2008, 34). I ask this question because it seems as if those who want to justify the exploitation of animal life as well as those who demand its liberation are all gathered around the same screen-bottomed pan, as I was long ago, searching for something that exists elsewhere.

The creek bed that these different factions share in common is the version of the Animal constructed by the Greeks. This Animal is fundamentally different than human mammals and this distinction has played a crucial role in western society, religion and ethics, in order to describe human development, human purpose and human uniqueness.

Though there were a wide variety of Greek perspectives on animal life and its shared relationship with human existence, the dominant views that shaped western science, philosophy and theology emphasized sharp distinctions between human and animal predominantly regarding reason, soul and language (Saelid Gilhus 2006). 
Aristotle created a hierarchy based on reason, by which higher humans could use lower plants and animals in any way they saw fit. The Stoics also emphasized the higher faculties of humans while denying animals the power of reason, and thus the ability to participate in social contracts and relationships of responsibility. This denial fit easily into Jewish and Christian narratives of dominion and justice, which affirmed the uniqueness of humans made in the image of God, while designating the rest of the soul-less biological world for human use (Sorabji 1993). Descartes' logic built upon these foundations, asserting that because animals could not speak, they could not reason, and therefore could not have a soul. Per Descartes, animals were pure automatons, machines without feeling or thought, utterly different from human life, who could be used without regard.

With a pan full of this Greek inheritance-and all the subjugation and control that it has led to for animals in agriculture, biological research, food, fashion, entertainment and as family companionsit's no wonder that many people in different disciplines with different motivations began shaking the pan back and forth, certain that there was something more to this version of the Animal handed down to them. And it's no surprise that some of the key insights crucial for breaking down the fortified wall between humans and animals came from those people who participated in institutions that were dependent on the subjugation, classification, coercion, ownership and caging of animals.

For example, biologists who relied upon the Greek classification system of phyla in order to categorize organisms according to structure, function and growth, also endorsed Darwin's narrative of co-evolution, which blurred, if not removed, any rigid line between species. Thus, biologists who were originally dependent upon a line of separation began to dismantle that same line as their learning progressed .

Animal behaviorists, whose research often depended upon the capture and observation of other beings, began erasing the line between the Animal and humans as they observed how tool use, 
language, social politics, altruism, morality and the presence of an emotional life exists in multiple species (de Waal 2007, Bekoff 2007).

Farmers and ranchers, who had spent years breeding, raising and slaughtering farm animals began seeing the similarities between themselves and members of their herds and flocks, in terms of their ability to experience physical pain and emotional distress (Lyman and Merzer 2001, Latham and Mason 2008, Newberry and Swanson 2008).

Philosophers, who were the direct descendants of Greek metaphysics, including the separation of the Animal from humans, began applying their deductive and inductive skills to the environment, and multiple disciplines emerged such as ecofeminism, deep ecology, environmental studies, posthumanism and process thought, which sought ways to bring animals back into a balanced relation with the human community as well as the rest of the environment.

Religious adherents, whose own communal history often depended upon a stark line between the Animal and human, began questioning this line as a valid criteria for inclusion into the spiritual community, and set about reinterpreting and mining their texts and traditions for fresh ethical mandates by which to engage contemporary relationships between human and animals (Waldau and Patton 2006).

Neuroscientists, whose discoveries frequently depended on invasive studies into the bodies and brains of other animals, began to realize that interacting with animals positively affected human wellbeing through decreased blood pressure (Baun, et al 1984); reduced anxiety levels for those with psychiatric disorders (Barker and Dawson 1998); improved psychological well-being of institutionalized elderly (Colombo, et al 2004); stress reduction in healthcare professionals (Barker, et al 2005); resilience to trauma within families as well as enrichment for family and couples therapy (Walsh 2009). 
The rise of companion animals, which depended on the capture, taming, transport, and genetic modification of animal life, has also created a locus of blurred identity. Animals are now firmly established in human homes and families, sleeping on human beds, traveling in automobiles, and even going to the workplace.

The great paradox of the well-defined line erected by the Greeks, by which animal life was captured and controlled, was that it led to circumstances of proximity and intimacy that undermined absolute distinctions between species and identities. To return to the metaphor, the firm distinction excluding animal life from human existence at the bottom of the creek bed, when scooped up in the screen-bottomed pan, began falling through the holes. As people began sifting through the ontological premises of fundamental difference, hierarchy and unimpeded use derived from the dominant Greek views, versions of the Animal were slipping through the screen at every point. The alleged line was not a physical barrier at all, but a site around which a Discourse of the Animal began to develop in myriad ways.

French philosopher, historian, and sociologist Michel Foucault lends insight to this phenomena in his analysis of the Discourse of Sexuality. According to Foucault, what made sexuality taboo was not a firm barrier of exclusion that effectively silenced sexuality's influence, but rather "lines of penetration" that "provided places of maximum saturation" (Foucault 1990, 47). According to Foucault, 17th century bourgeois society made an attempt to control sex at the level of speech and minimize its public discussion. However, this effort actually intensified the discourse on sex.

Religious confessionals began hearing details, not just about sexual acts, but also desires, thoughts and dreams which were now brought into discourse. Sex became a subject for rational study, classified and understood as statistical phenomena. The sex lives of citizens became part of public welfare in terms of population assessments, birth rates, fertility and illegitimate births. Children's sexuality took on new importance and schools began teaching sex 
education as well as separating children by gender and enforcing curfews. Additionally, the crude discourse that had previously been used to discuss sex was replaced by a number of complex discourses that required expertise and technical language, including medical, psychological, or legal terminology, that placed stricter controls on the subject matter while categorizing new levels of trespass and perversion along with treatment and punishment.

If we take this description of modern sexuality as an instructive, if unexpected, starting point for evaluating the removal of the Animal from the sphere of human life-as initiated by the Greeks-we see that this line of exclusion also allows multiple points of entry while necessitating further types of explanatory discourse. By excluding the Animal from the realm of human life and moral consideration, the Greeks and their progeny actually created multiple lines of penetration whereby versions of the Animal crept into human society at numerous points.

The more the Animal (or sexuality per Foucault) was supposedly excised from human socio-biological life, the more its influence permeated every turn of that life in the form of symbolic discourse. Perhaps because of its exclusion, the Animal became a subject of interest for multiple disciplines from farming to biology, philosophy and religion to neuroscience and the pet industry. And gradually the symbolic presence of animals seeped into every aspect of visible culture.

The Animal was behind bars in zoos and caged in classrooms. She was in circuses, on advertising billboards and mascots for sports teams, political parties and fraternal organizations. The Animal was displayed on cable television shows and in animated cartoons. The body of the Animal was utilized to test drugs, household cleaners and surgical techniques. Magazines were developed for pet lovers and breeders. Recipes were collected and transmitted to those who liked to cook the Animal's flesh. Veterinarian practices became ubiquitous. The Animal was bred and slaughtered as part of 4- $\mathrm{H}$ county fairs, and displayed by children for prizes. Animal health insurance industries 
developed. Animal rescue and advocacy organizations became more prevalent as did interest in animal chaplaincy and animal philosophy courses. Children's books, fables, songs, stuffed toys and video games depicted the Animal. Clothing and footwear was marked with animal images as well as being made of flesh, fur or feathers. The sciencefiction-esque magnitude of the modern meat, egg and dairy industries, along with the influence of food culture, made the Animal and her flesh and fluids an unquestioned part of consumer society.

The Animal who had been excluded by the Greeks now existed on and as our clothing, shoes, belts, bags and hats. She was in our entertainment, within our homes, families, educational systems, political and environmental agendas, and on our plates. The excluded Animal was now utilized to sell virtually every idea under the sun, including the consumption and exploitation of her own flesh.

This Animal that exists all around us is a reflection of what remains atop the screen as excluded and what slips through as part of the Discourse of the Animal that surrounds our lives at every turn. Both the rocks remaining atop and the water, sand, and grit falling through the screen compose the Animal that is captured in an imaginary line of exclusion around which, claims Foucault, a "multiplicity of discourses" and "manifold mechanisms which, in the areas of economy, pedagogy, medicine, and justice," (to name but a very few), "incite, extract, distribute and institutionalize" an "immense verbosity" that captures the Animal (Foucault 1990, 33).

While the gold of actual animal life still eludes us, the Discourse of the Animal surrounds us on all sides of the screen as excluded or included in particular ways suitable to human society. Around the screen are gathered those who want to justify the ongoing exploitation of the Animal and its exclusion from ethical debate, as well as those who demand its liberation or, at the very least, some measures for including it in moral considerations. We have technical ways to talk about the Animal, formal ways to study her, to argue over her, to justify her captivity or demand her freedom, using surprisingly similar language; a similar understanding whether we 
want to eat the animal or venerate her. This tug of war proliferates the Discourse of the Animal by adding new lines of penetration and language that rest upon and perpetuate certain accepted premises.

One of those premises in western society is the understanding of a political subject with personal power, a characteristic differentiated from other philosophical and theological worldviews (Mill 1913). The political subject is often seen as a particular individual who can rise above their community and ecosystem, like a child who leaves his family in the dust. He can pursue life, liberty and happiness; he is capable of participating in political and juridical responsibility. He is seemingly unencumbered by the actual cycles of life although he has classified and categorized its appearances.

In addition to being merely political, he can pursue spiritual enlightenment by dissociating from his surroundings and aspiring toward a God's eye view, as from outside, unaffected. Being unaffected, unattached, and sovereign is his own being, he has infinite power and total agency; he can transcend matter by his will.

This is one of the significant premises of western society and it provides a foundation for the Discourse of the Animal. Against this premise of a political subject with personal power, the Animal in and slipping through screen-bottomed pan has been measured by its detractors and supporters for the last two thousand years. By privileging an individualized political subject as the most ideal form on earth, second only to a perfected God (God's vice regent per Islam, steward per Judaism and Christianity, the apex of evolution and morality per science and humanism), all our discourses close out the possibility of an ecological being who is somehow an individual but who also belongs - who affects and is affected, a part and a wholewhose power rests in contributing to and receiving from its surroundings rather than being separate from them. Within the Discourse of the Animal, ecological beings (quite different from dominant definitions of political subjects) will always appear lacking or incapable of an independent relationship with deity or the state. 
They will appear powerless when compared to the power of the political subject.

Gathered around the screen-bottomed pan and its exclusionary line, the Discourse of the Animal may sound different depending on who is speaking for or against animals, but its premises are often similar to what I have described. On the one hand a negation: The Animal is not an agent, she cannot act politically, she cannot affect human existence or evolution, she cannot assume responsibility, she cannot speak in her own defense, she cannot choose, she is not free, she cannot exert power. And by this we subjugate her. On the other hand an affirmation: The Animal can be a political agent, she can act and even speak if we would only include her in our sphere as a political subject with personal power. And by this we seek her liberation.

This is the extent of the Animal that remains trapped around the screen, whether the stones atop or the dregs falling through at points of penetration. To be or not to be a political subject is often the nature of the argument. The line we, who care about animals, are blurring is not really between human and animal. We are blurring the line between human as political subject, and the Animal who we think should join us as a political subject, though admittedly a subject with little power: Wearing the clothes we see fit, submitting to the laws we practice, sharing in the rights we have constructed, leashed and surgically altered to avoid reproduction, kept inside houses and apartments we've built, starring in our movies, living in our barns or backyards, eating food that we provide, over-feeding and overbreeding in the way customary for us. This Animal is brought into our neuroscience labs so we can learn about human behavior and she is brought into our behavioral labs so we can learn about animal tool use. She is brought into our churches to receive our blessing, captured under the expressions of our personal power.

But lest we forget, there is still an Animal we haven't found, like the elusive gold of my childhood creek, that is more than the stones atop the screen or the water and sand falling around us. And this 
being has been more or less ignored. And frankly we don't know much about it. We've never really gotten a look so we aren't sure how it's different from the Animal we see on our side-the one in the factory farm or the one in the flannel jacket at the dog park-and to tell the truth, we don't even know what it might be called over there, if anything at all, or how it might affect us.

But I suggest we leave the screen for a moment, along with the Discourse of the Animal rooted in the underlying premise of the political subject with personal power, and resume our search for gold, if only for a moment, to see if we discover something more valuable about the many elusive lives we share this planet with.

Two-hundred thousand years ago, our ancestors were animals themselves, upright bipedal primates who walked out of the African forests that had withered during the Ice Age into the surrounding grasslands, vulnerable and exposed. They watched the activities and rhythm of other mammalian groups, observing and mimicking their techniques so that they might survive among them as huntergatherers. This process of our brain-making required constant scrutiny of other animals (Daly-Olmert 2009, 3). Early Paleolithic hunters were far from the top predator, literally overwhelmed by herds of deer, early cattle, as well as the large carnivores. Outnumbered, outsized and outmatched in strength and speed, early humans were a precarious group watching and learning from other communities who were flourishing: How to move with the seasons; how to hunt as a group; where to get water; what fruit and berries to eat (Daly-Olmert 2009, 2-9).

Where they lacked claws and sharp teeth, they developed spears and daggers. Where they lacked the armor of other beings, they developed shields. Early humans mimicked the movements, the silence and the sounds of animals. In his book Singing Neanderthals, Steven Mithen describes how ancient tribes mimicked animals in game, songs and dance, replicating their actions, calls, and physical 
features in the length of a stride, the angle of a forearm, the turn of a head, the duration and pitch of a note (Mithen 2006, 168-71).

Biomimicry has been the rule of our animal evolution with other beings, a blurring of identities that has shaped the brains and bodies of all parties involved. Early widespread cave drawings depicting half -upright human/half-creaturely beings, evidence of shamanic traditions and beliefs, show the centrality of this blurred identity, and for good reason. As the twentieth-century Vedantic Hindu scholar Sri Auribindo put it:

[I]n the animal, operations of a perfect purposefulness and an exact, indeed a scientifically minute knowledge which are quite beyond the capacities of the animal mentality and which [the human] can only acquire by long culture and education and even then uses with a much less sure rapidity (Auribindo 2000, 88-89).

In other animals we find a near perfect purposefulness; a knowledge that does not have to think itself because it just is. Our ancestors knew this well, so much so that not only did they observe and mimic animals from a distance, but they tried to become like them, taking on the animal mind, as depicted in shamanic drawings and Egyptian metaphysics. Animals were not allegory, fable, and myth as in our traditions. They functioned as individual ecological teachers in the natural world, embodied sages who taught us about the mutual relations of all the beings around us, something Darwin noted, in On the Origin of the Species that modern humans have "profound ignorance" of (Darwin 2008, 143).

We tried to become like them and they also moved nearer to us, so that 40,000 years ago, in Europe, early humans began to associate with local wolves, cooperating in hunting, beginning the slow, mutually trusting activity of being domesticated by one another. Wolves could scavenge outside the dwellings of early humans and eventually moved inside to seek shelter-gradually, over generations-and humans slowly utilized the help of wolves-who 
could warn off predators, help with hunting, provide warmth, carry loads and even supplement the food supply when necessary.

The power in those relationships was necessarily shared, though perhaps not always equally. But the gaze went both ways-a fourlegged being was observing a two-legged being; the two-legged watching the four-legged-each coming to see the other as an advantageous part of their own group's survival. When we consider how central the ecological example of the natural world and the animals within it was for the development of early humans, we can understand why Leonardo Da Vinci might have have warned, "Those who are inspired by a model other than Nature, a mistress above all masters, are laboring in vain" (Da Vinci 1883, 332).

What comes next is not a seamless narrative, as few narratives are. About ten- thousand years ago, human animals assumed the habit of living in more or less permanent settlements, and the lessons learned from tens of thousands of years of mimicry would provide our ancestors the knowledge of breeding cycles, diseases and behaviors of young animals as well as knowledge of plant productivity so that agricultural technology could begin. For some cultures this manipulation of life was yet still a form of shared power, not yet the bio-power domination that it would one day become in western society under the Discourse of the Animal. In some remote places even today, agriculture means being attuned to the wisdom of an animal's body. For much of the world, however, this attunement is lost. In fact, it was just rediscovered that cows, known and worshipped by the ancients for their ability to forecast weather, also have a magnetic orientation northward without need for a compass. They are the compass (Peterkin 2008).

How much evidence of this perfect purposefulness do we need? While we congratulate ourselves on the development of the iPod, other beings are coordinated instruments of relationship and environment. Whales, dolphins, and salmon navigate in the deeps when visual cues like the sun and stars are not visible, using something called magnetite, an iron oxide found in deep water which, 
as you might have guessed, is magnetic. Loggerhead turtle hatchlings orient themselves not long after birth to Earth's magnetic field that guides them throughout their migration and allows them to return to the exact location where they hatched to lay their eggs. Coral reefs bloom with the timing of the moon; Canadian geese migrate with the seasons and the changing celestial sky, both without calendars. Rats, weasels, snakes, centipedes and dogs can detect seismic activity before it occurs (Kirschvink 2000).

The beings who are not confined to the screen-bottomed pan are ecological wonders that cannot be quantified by discourses and arguments that constitute or even dispute them as edible, ownable, accessible, or controllable. Rather these beings are individuals who exist beyond these categories, often attuned to voices that we cannot hear, "gifted with," to use to words of naturalist Henry Beston, "extensions of the senses we have lost or never attained" (Beston 2003, 25).

I'd like to close by looking at a moment when our understanding of the Animal at the screen collided with our realization that there was something more to the individual beings under our observation; when those relying on the multiplicity of mechanisms and symbols that make up the Discourse of the Animal also glimpsed a glint of gold-a version of the Animal, whatever it may be, that still waits to be found.

In the 1960s, Harry Harlow embarked on his controversial primate studies in order to demonstrate the necessity of love in social animals. It could only be humans who needed proof of such a thing. Yet, Harlow sought to disprove the psychological wisdom of the day that instructed parents to minimize contact comfort with their children from infancy onward. Prevailing thought suggested a brief pat on the back was sufficient to express care. Mothers and family life were not viewed as essential to the healthy development of a political subject with personal power. Harlow, estranged from his own family, was intent on showing the scientific community that something 
intangible and immeasurable, like love, indeed had enormous impact on the development of life (Harlow 1958).

Rhesus monkeys were removed from their mothers at a few weeks of age and placed with two wire surrogate mothers. One surrogate mother was only made of exposed wire but offered milk. The other surrogate mother offered no milk, but her wire body was covered with a soft terrycloth. If it was food alone that drove the infant's behavior, it would make sense that the young rhesus monkeys would spend most of their time with the wire mother who had the bottle. On the contrary, the infants spent the bare minimum time with the bottle and the majority with the cloth-covered mother whose softness they could cling to.

Harlow's studies tested this in troubling ways, showing for example, that even when the cloth mother delivered a painful shock to the infant, the young monkeys would clamber back toward her softness and comfort. When left in a new environment, infants who were with the cloth mother would slowly explore the new space, returning as needed to the familiar safety of their soft cloth, exploring more and more on each venture. When the cloth mother was suddenly removed, the rhesus infants would scream and curl up, rocking themselves, pulling their hair. The introduction of the mother made of exposed wire with milk did nothing to calm their distress or reactivate their curiosity.

It is so like us humans to project our disconnections on the lives of other beings, to try and make them more human, so that we can understand ourselves better. We relegate them to the brutal, the "red in tooth and claw" (Tennyson 1850), the mechanistic, the devalued instinct, the stupid, the body allegedly limited by its animal nature, as we claim the ability to pursue the world of the gods, to take on the body of the gods, to transcend the mire of this material world of bodies, pleasures, pains, co-dependence and love.

In the lab or the factory farm, in our companion animals, in pet shops, in zoos and circuses, in advertisements and on clothing, we are 
surrounded by beings who are victim to a Discourse of the Animal based on a political subject with personal power. We remove these beings from the vital maternal and ecological identities in which they are near perfect instruments of belonging and shared power. Yet even still, as in the case of the rhesus monkeys, their wisdom shines forth in spite of the restrictions and limited expectations we place upon them. This wisdom and knowledge is available for those of us who have eyes to see or who bravely (if hesitantly) set aside our gaze so that we might "see" more rightly the relational wisdom-could we call it love? - that we must have proven to us, but which other beings just are. In his "Four Quartets", T.S. Elliot wrote:

With the drawing of this Love and the voice of this Calling We shall not cease from exploration And the end of all our exploring Will be to arrive where we started And know the place for the first time. Through the unknown, unremembered gate When the last of earth left to discover Is that which was the beginning; At the source of the longest river The voice of the hidden waterfall And the children in the apple-tree Not known, because not looked for But heard, half-heard, in the stillness Between two waves of the sea. Quick now, here, now, always-A condition of complete simplicity (Costing not less than everything) And all shall be well and All manner of thing shall be well... (Elliot 1968, 59)

Can we choose to forego the generalizations handed down to us about the Animal and instead remain oriented to the vast unknown realities of particular beings who contribute to and are shaped by particular relationships in particular environments? Can we accept that these particular beings are not much known because they have not been looked for, even as their bodies and minds are multiple expressions of the One life, spirit and truth in which so many of us long to dwell? Must we revert to the screen of exclusion and political 
inclusion given to us by the Greeks, and the Discourse of the Animal surrounding it, while remaining blind to the pleasures, pains and relational knowledge of beings whom we so desperately need to learn from?

The bumblebee at the crab apple blossom, the squirrel chattering in the oak, the dog at the foot of our bed, the spider in the garden, the chicken on our plate, are not mere ornament or intrusion to human life. Rather, they are snapshots of resistance to the capture of their bodies and ecological insight, as well our own. Reevaluating those aspects of our culture, tradition and habits that claim to blur the human/animal line-be they science and technology, animal behavior studies, neuroscience, philosophy, religion and spirituality, our companion animals, our consumption, our contemporary animal rights-without the aid of the Discourse of the Animal is the challenge for our time and it will be costly indeed.

But it is only in doing so that we might truly discover what other beings can teach us and what we ourselves may be capable of knowing, doing and becoming when we liberate the bodies and life of other beings from the burden of our categories and language. By releasing other beings from our discourse, we may liberate themand perhaps ourselves-in ways more fundamental than opening up every cage, though certainly, physical freedom is a logical result.

In their bodies we see a relational life form with relational power, a composite subject who exacts a cost and tenders a contribution-a key with a lock, an inner with an outer, a god with a world, a departure with an arrival, back where we started, knowing the place for the first time.

When we look into the space deep within the eye of another being, whose language we cannot yet speak, whose sounds we cannot yet interpret, whose perspective we can only endeavor to inhabit, what is it that we are looking for, listening for, half heard in the stillness? Oh, that it would not be another word for our Discourse, but here, now, 
always, a condition of complete simplicity-a glint of gold to lure us on.

\section{References}

Auribindo, Sri. 200o. The Life Divine. Twin Lakes: Lotus Press.

Barker, Sandra B. and Kathryn S. Dawson. 1998. The effects of animal-assisted therapy on anxiety ratings of hospitalized psychiatric patients. Psychiatric Services, 49 (June): 7.

Barker S. B., Knisely J.S., McCain N.L., Best A.M. 2005. Measuring stress and immune response in healthcare professionals following interaction with a therapy dog: a pilot study. Psychology Reports, 96 (June): 71.

Baun, Mara M., Nancy Bergstrom, Nancy F. Langston, Linda Thoma. 1984. Physiological effects of human/companion animal bonding. Nursing Research, 33 (3): 126-29.

Bekoff, Marc. 2007. The emotional lives of animals. Novato CA: New World Library.

Beston, Henry. 2003. The outermost house: A year of life on the great beach of Cape Cod. New York: Henry Holt and Company.

Colombo, Giovanni, Marirosa Dello Buono, Katya Smania, Roberta Raviola and Diego De Leo. 2006. Pet therapy and institutionalized elderly: A study on 144 cognitively unimpaired subjects. Gerontology and Geriatrics, 42 (2): 20716.

Daly-Olmert, Meg. 2009. Made for each other: The biology of the human-animal bond. Cambridge: DeCapo Press.

Darwin, Charles. 2008. On the origin of the species. In Darwin: Evolutionary writings. Oxford: Oxford University Press.

Da Vinci, Leonardo and Jean Paul Richter. 1883. The literary works of Leonardo Da Vinci. London: S. Low, Marston, Searle \& Rivington.

Derrida, Jacques. 2008. The animal that therefore I am. New York: Fordham Press.

De Waal, Frans. 2007. Chimpanzee politics: Power and sex among apes. Baltimore: The Johns Hopkins Press. 
Elliot, T. S. 1968. Little Gidding. In Four Quartets. Orlando: Harcourt, Inc.

Foucault, Michel. 1978. The history of sexuality: An introduction, Volume One. New York: Vintage Books.

Harlow, Harry. 1958. The nature of love. American Psychologist 13 (December): 673- 685

Kirschvink, Joseph L. 2000. Earthquake prediction by animals: Evolution and sensory perception. Bulletin of the Seismological Society of America 90 (April): 312-23.

Latham, Naomi R. and G.J. Mason. 2008. Maternal deprivation and the development of stereotypic behavior. Applied Animal Behavior Science 110 (March): 84-108.

Lyman, Howard F. and Glen Merzer. 1998.Mad cowboy: Plain truth from the cattle rancher who won't eat meat. New York: Touchstone. Mill, John Stuart. 1913. On Liberty. New York: Longmans, Green and Co.

Mithen, Steven J. 2006. The singing Neanderthals: The origins of music, language, mind and body. Cambridge MA: Harvard University Press.

Newberry, Ruth and Janice Swanson. 2008. Implications of breaking mother-young social bonds. Applied Animal Behavior Science 110 (March): 3-23.

Peterkin, Tom. 2008. Cows automatically point to the north. Telegraph.Co.Uk, August 26.http://www.telegraph.co.uk/news/newstopics/howaboutthat/2623809/ - point-north-thanks-to-in-built-compasses.html. Saelid Gilhus, Ingvild. 2006. Animals, Gods and humans: Changing attitudes to animals in Greek, Roman and early Christian Ideas. New York: Routledge.

Sorabji, Richard. 1993. Animal minds and human morals: The origins of the western debate. New York: Cornell University Press.

Tennyson, Alfred Lord. 1850. Canto LVI. In In Memoriam A. H. H. The Literature Network, http://www.onlineliterature.com/tennyson/718/?term=red+in+tooth.

Waldau, Paul and Kimberley Christine Patton. 2006. A communion of subjects: Animals in religion, science and ethics. New York: Columbia University Press. 
Walsh, Froma. 2009. Human-animal bonds II: The role of pets in family systems and family therapy. Family Process 48 (December): 480-99. 